\title{
Modelling a Human Well-Being Indicator
}

\author{
$\underline{\text { S. Abidin }}^{\text {a }}$, C. Zhang ${ }^{\text {a }}$ and D. Foo ${ }^{\text {a }}$ \\ ${ }^{a}$ Department of Finance, Waikato Management School, The University of Waikato, Hamilton, New Zealand \\ Email: sazali@waikato.ac.nz
}

\begin{abstract}
This paper analyses the Happy Planet Index (HPI) as a new human well-being indicator, and its deterministic relationships with a range of macroeconomic, social, and political factors. In addition, this paper identifies any lead-lag relationships between the variables studied. This study employs a panel data comprising 25 OECD countries over a period of 16 years from 1994 to 2009. The deterministic relationships are modelled with Pooled Ordinary Least Square (POLS) regressions, and any lead-lag relationship is identified by applying Granger causality tests to the panel dataset. This study finds that conventional macroeconomic indicators such as GDP per capita, unemployment rate, and inflation rate are statistically significant in explaining HPI, though the relationship is negative. Overall, the selected variables are successful in explaining HPI. The study also finds significant causal relationships between HPI and some of the variables. This paper contributes to the literature by studying a relatively new human well-being variable, and by using a panel dataset which significantly increases the power of the tests.
\end{abstract}

Keywords: Well-being, determinants, causality, economy, sustainability 


\section{INTRODUCTION}

Traditionally, measures of national income are used as success indicators of a country, and personal income level is widely used as a proxy for the well-being of its people. In recent years, however, the inadequacies of traditional economic parameters in measuring human well-being have been widely acknowledged. People are increasingly aware of the fact that in addition to economic performance, a range of social, political, and cultural factors also have significant impact on the well-being of a country's people. Alternative measures incorporating a wider range of factors in addition to economic parameters are developed, such as the United Nation's Human Development Index, which combines indices of life expectancy, education and GDP per capita (Ng, 2008). More recently, facing global climate change and resource depletion, environmental and resource sustainability draws increasing amount of attention, that the pursuit of well-being in this generation should not compromise future generations' ability to do so. A new development in the measurement of human well-being is the Happy Planet Index (HPI), the purpose of which is to better reflect life experience and more importantly, the environmental sustainability of such experience.

Happy Planet Index (HPI) was first introduced by the New Economic Foundation in 2006 as an index of human well-being and environmental impact (Marks et al. 2006). Based on the foundation that people want to live long and fulfilling lives, HPI was compiled incorporating three separate indicators: life-satisfaction, life expectancy, and ecological footprint, and ultimately to reflect the average years of happy life produced by a given nation, per unit of planetary resources consumed (Calculating the HPI, 2011). HPI does not measure the happiness, level of development, or environmental friendliness of a nation, but combines all three to measure the "provision of long-term well-being without exceeding the limits of equitable resource consumption" (HappyPlanetIndex, 2011). In essence, HPI shows the relative efficiency with which nations delivers human well-being (Marks et al. 2006). As a relatively new indicator, HPI has received few studies in the academic field. Of particular interest are its relationships with conventional economic, social and political indicators, and any lead-lag relationships it may have with other indicators. The purpose of this paper is to uncover potential deterministic and lead-lag relationships HPI may have with some important macroeconomic, social and political indicators. Specifically, this paper will study HPI's relationships with 9 macroeconomic, social and political indicators, based on a sample that including all OECD countries over the period from 1994 to 2009.

In this study, any deterministic relationships HPI have with other variables are modelled using pooled Ordinary Least Square (POLS) regression, which explains how the independent variables individually and jointly determine the dependent variable. In addition, Granger Causality tests are performed to identify any lead-lag relationship between HPI and other variables. This study is based on a data sample of OECD countries. This study contributes to the literature in a number of ways. First of all, to our knowledge, this is the first academic study that systematically analyses the new well-being measure, Happy Planet Index, and its interactions with other conventional economic, social, and political indicators. Secondly, this paper employs panel data analysis, which witnessed rapid development in analysis techniques in the past decade.

This paper is organised as follows. Firstly, it presents a brief review of relevant literature on the study of human well-being, its relationships with other factors, and the new Happy Planet Index. Research data are introduced in Section 3. Research methodology of this study is explained in Section 4. Section 5 presents the main findings, with conclusions and research implications drawn at the end.

\section{LITERATURE REVIEW}

With increasing economic growth, an increasingly affluent world in the twenty first century starts to witness ecological constraints i.e. scarcity of resources and environmental pollution, which threaten to stop growth. Examples include the end of the age of cheap oil, the emerging global warming that could cause substantial damage by the end of the century. Leaders around the globe consequently start to re-examine the modern development paradigm and seek out ways to avoid the possible collapse of modern civilization. Moreover, emerging economies found themselves in a position to choose a balanced approach to modes of production (Abeygunawardana, 2010). Traditionally, GDP per capita has been most frequently used as a measure for economic wealth, and GDP per capita is arguably the most important proxy of standard of living, though the founders of the concept have explicitly warned against it being used to function as one. Criticisms based on economic considerations state GDP measure is insensitive to income distribution and fails to distinguish costs incurred in compensating for undesirable events.

More recently, GDP's inadequacy as a measure of human progress is highlighted. As is repeatedly shown since Easterlin (1974), GDP growth may not necessarily increase experienced well-being. Moreover, GDP does not provide account for exploitation of and damage to the natural environment, meaning that GDP is 
inadequate in measuring sustainable welfare (Thompson, et al, 2007). Although it is widely supported that higher levels of wealth are usually coupled with higher levels of well-being, it remains to be seen if it correlates to high efficiency in delivering well-being. There have been numerous studies analysing the relationships of happiness with other macroeconomic parameters, including inflation, and unemployment rate, and have generally found negative relationships between them and happiness (see DiTella et al., 2001, Frey and Stutzer, 2002, Blanchflower, 2007). Previous studies have also found evidence supporting a negative relationship between income inequality and happiness (see Kenny, 1999).

New Economics Foundation developed Happy Planet Index (HPI) to be a multidimensional index that determines a measure of happiness based on environmental impact and well-being. The index shows how efficiently a nation converts their share of natural resources into longer and happier lives for their citizens. Interestingly, and in contrast to conventional economic-based measures, developed countries generally do not rank high in the index, due to their generally large "ecological footprint" (What is HPI, 2010).

\section{DATA AND DESCRIPTIVE STATISTICS}

This study uses the Happy Planet Index as the primary variables to represent sustainable well-being of people of a particular country. The New Economic Foundation publishes HPI data on 143 countries in 5-year interval, except for OECD countries where annual data are available. This study thus uses a sample of all 25 OECD countries and a sixteen-year sample period from 1994 to 2009 is selected. The performance of OECD countries, despite their advanced economies and high national income, is unremarkable. The OECD-average HPI over the 16-year period also show that HPI experienced significant drop in the 1990s despite rapid expansion of the economies, indicating that high growth does not necessarily brings about ecological efficiency in delivering human well-being.

To analyse the relationships HPI may have with macroeconomic, social, and political factors, a panel of ten indicators are included in the study, including: GDP per capita (GDP), Inflation (INFL), MSCI index (MSCI), Unemployment rate (UEMP), Average annual hours worked (AVHR), the Gini Coefficient (GINI), Political Terror Scale (PTS), Corruption Perception Index (CPI), Inflow of international immigrants, and Outflow of international immigrants. In addition, Political Terror Scale and Corruption Perception Index are included as political and social factors in the analysis, and are expected to have a negative relationship with HPI. A brief summary of the descriptive statistics of the dependent and independent variables is provided in Table 3.1.

Table 3.1

\section{Descriptive Statistics of dependent and independent variables}

HPI - Happy Planet Index; GDP - GDP per capita; MSCI - MSCI index, UEMP - unemployment, INFT inflation; AVHR - average annual hours worked; CPI - Corruption Perception Index; INFL, OUTFL Inflow/Outflow of international immigrants; PTS - Political Terror Scale; GINI - Gini coefficient

\begin{tabular}{c|ccccccccccc}
\hline OECD & HPI & GDP & MSCI & UEMP & INFT & AVHR & CPI & INFL & OUTFL & PTS & GINI \\
\hline Mean & 40.90 & 32306.09 & 1143.29 & 6.51 & 106.72 & 1726.54 & 7.48 & 174.64 & 75.66 & 1.68 & 30.03 \\
St Dev & 6.50 & 16502.34 & 1152.73 & 3.36 & 25.92 & 217.36 & 1.93 & 237.92 & 134.16 & 0.76 & 5.93 \\
Min & 22.03 & 3483.26 & 51.80 & 1.01 & 27.70 & 1348.00 & 0.00 & 3.30 & 0.00 & 0.00 & 20.00 \\
Max & 61.34 & 126892.70 & 7386.04 & 24.12 & 236.99 & 2658.00 & 10.00 & 1266.26 & 638.96 & 4.00 & 53.25 \\
Skewness & -0.02 & 1.41 & 1.99 & 1.56 & 1.76 & 1.57 & -1.22 & 2.18 & 2.72 & 0.87 & 1.43 \\
Kurtosis & 1.00 & 4.57 & 5.11 & 4.55 & 4.95 & 4.31 & 1.35 & 4.55 & 7.03 & 0.38 & 2.73 \\
\hline
\end{tabular}

This study uses a panel data comprising 25 OCED countries over a period of sixteen years from 1994 to 2009 with 4316 observations. A number of advantages have been identified with panel data application, including the ability to address a broader range of issues and more complex problems, and particular to this study, the ability to study dynamic relationships between variables when only a short period of data is available (Brooks, 2008). As most variables included in this study are published in low frequency (annually), and some indices have a relatively short history, the application of panel data analysis techniques allows us to explore lead-lag relationships by performing Granger Causality test which would have been impossible without sufficiently long time series. 


\section{RESEARCH METHODOLOGY}

\subsection{Pooled Ordinary Least Square Regression}

The Pooled Ordinary Least Squares (POLS) regression analysis is the primary research technique in this study to study the cross-section of the independent variables and the dependent variable. As the study object is sustainable well-being, the HPI index figures serve as the dependent variable, while the macroeconomic parameters are the independent variable. The design of the OLS regression equation is as follows:

$$
\begin{aligned}
\mathrm{HPI}_{i t}= & \alpha+\beta_{1 t} \mathrm{GDP}_{i t}+\beta_{2 t} \mathrm{MSCI}_{i t}+\beta_{3 t} \mathrm{UEMP}_{i t}+\beta_{4 t} \mathrm{INFT}_{i t}+\beta_{5 t} \mathrm{AVHR}_{i t}+\beta_{6 t} \mathrm{CPI}_{i t}+\beta_{7 t} \mathrm{INFL}_{i t}+ \\
& \beta_{8 t} \mathrm{OUTFL}_{i t}+\beta_{9 t} \mathrm{PTS}_{i t}+\beta_{10 t} \mathrm{GINI}_{i t}+\varepsilon
\end{aligned}
$$

where $\mathrm{HPI}_{i t}$ is the dependent variables, $\beta$ is a $10 \times 1$ vector of parameters to be estimated on the explanatory variables, $i=1, . ., 25 ; t=1, \ldots, 16$.

\subsection{Granger Causality test}

To identify any lead-lag relationship between HPI and the explanatory variables, Granger causality test is conducted on the dataset. The introduction of a panel permits the use of both cross-sectional and time-series information for testing the causal relationship between two variables, by increasing the number of observations (Hoffmann et al, 2005). Before Granger causality tests are conducted, unit root tests are carried out on the series. This study conducted the first generation tests where the restriction is in place, namely Levin,Lin \&Chu test, Im, Pesaran and Shin W test, ADF - Fisher test, and PP - Fisher test. The results of unit root tests and Granger causality test are presented in Section 5.

\section{FINDINGS AND DISCUSSIONS}

\subsection{Pooled Ordinary Least Square Regression}

The results of the Pooled Ordinary Least Square (POLS) regression are presented in this part. To avoid any potential heteroscedasticity, we decide to use heteroscedasticity-consistent standard errors in the POLS analysis. The results of the POLS analysis are presented in Table 5.2. As the first step of the regression analysis, five macroeconomic indicators are included as independent variables. The results show some important relationships. Firstly, we find a negative relationship between GDP and HPI. This is an interesting result, showing that as the income level of a country increase, the ecological efficiency of delivering human well-being decline. The result is statistically significant at one percent confidence level. This shows that among OECD countries, which comprises mainly of developed countries, improvements in human wellbeing are usually achieved at the cost of larger ecological footprints. This is consistent with the New Economic Foundation research that OECD countries that despite an overall improvement of fifteen percent in well-being from 1961 to 2005, the ecological footprint increased over seventy-two percent.

Secondly, inflation has a negative and significant relationship with HPI, consistent with intuition. Past studies have shown that inflation generally has a negative impact on perceived life satisfaction (Frey and Stutzer, 2002). Another statistically significant macroeconomic indicator that explains HPI figure is the MSCI Index. It would seem that stock market performance has a positive impact on the HPI, perhaps because wellperforming stock market brings higher perceived life satisfaction with little ecological impact. Finally, unemployment rate and average annual hours worked are both negatively related to HPI figure. The result shows that as unemployment and average annual hours worked increases, the ecological efficiency of wellbeing delivery deteriorates. Overall, the five macroeconomic indicators achieved a relatively high R-squared of 0.4237 , indicating that macroeconomic indicators have a strong explanatory power in predicting HPI.

As the next step, we introduce the social and political indicators into the regression. First introduced is the Corruption Perception Index, which measures the perceived level of corruption in a country. OECD countries have generally done well in this index. Intuitively, CPI should have a negative relationship with human wellbeing. This is supported by our analysis. CPI is found to have a negative relationship with HPI, showing that a lower level of corruption can increase well-being without impacting on the environment. Inflow and outflow of international immigrants are then included in the regression. Interestingly, inflow of international immigrants is associated with lower HPI, while outflow of immigrants is positively related to HPI. There may be associated social problems with inflow of immigrants that could lower perceived satisfaction in a country, or the inflow and outflow patterns may be indicative of wider social and economic realities. However, the coefficients of inflow/outflow lack statistical power even at ten percent significance level. 
Table 5.1

\section{Pooled Ordinary Least Square (POLS) regresion results}

HPI - Happy Planet Index; GDP - GDP per capita; MSCI - MSCI index, UEMP - unemployment, INFT inflation; AVHR - average annual hours worked; CPI - Corruption Perception Index; INFL, OUTFL Inflow/Outflow of international immigrants; PTS - Political Terror Scale; GINI - Gini coefficient. *** denotes confidence level at $1 \%, * *$ denotes confidence level at $5 \%, *$ denotes confidence level at $10 \%$.

\begin{tabular}{c|ccccc}
\hline GDP & -0.000145 & -0.000137 & -0.000148 & $4.46 \mathrm{E}-05$ & -0.000175 \\
& $(-7.570902)^{* * *}$ & $(-6.927148)^{* * *}$ & $(-6.145181)^{* * *}$ & $(1.189265)$ & $(-2.870717)^{* * *}$ \\
INFT & -0.057879 & -0.053515 & -0.005302 & -0.081158 & -0.081158 \\
& $(-5.603174)^{* * *}$ & $(-5.028507)^{* * *}$ & $(-0.218459)$ & $(-3.420462)^{* * *}$ & $(-2.675559)^{* * *}$ \\
MSCI & 0.003115 & 0.003092 & 0.003612 & 0.002033 & 0.003135 \\
& $(13.12295)^{* * *}$ & $(12.84952)^{* * *}$ & $(11.64163)^{* * *}$ & $(6.426116)^{* * *}$ & $(7.244861)^{* * *}$ \\
UEMP & -0.090251 & -0.123944 & 0.258218 & -0.120005 & -0.208317 \\
& $(-1.073894)$ & $(-1.364799)$ & $(1.568398)$ & $(-0.673847)$ & $(-1.027948)$ \\
AVHR & -0.001151 & -0.002377 & -0.001966 & -0.001389 & -0.007421 \\
& $(-0.819279)$ & $(-1.485425)$ & $(-0.915805)$ & $(-0.654439)$ & $(-2.136164)^{* *}$ \\
CPI & & -0.255511 & -0.227077 & 0.22801 & -0.004115 \\
& & $(-1.558827)$ & $(-0.817786)$ & $(0.726239)$ & $(-1.156603)$ \\
INFL & & & -0.000069 & -0.003709 & 0.001256 \\
& & & $(-0.020127)$ & $(-1.180056)$ & $(0.273785)$ \\
OUTFL & & 0.001503 & 0.003865 & 0.772463 \\
& & & $(0.321385)$ & $(0.920477)$ & $(2.012091)^{* *}$ \\
PTS & & & 1.361539 & 1.178081 \\
& & & & $(2.187342)^{* *}$ & $(1.476924)$ \\
GINI & & & & -0.097826 \\
& & & & & $(-0.778961)$ \\
\hline Residual & 50.791760 & 54.28659 & 45.69535 & 46.28956 & 61.29542 \\
& $(15.31053)^{* * *}$ & $(13.1856)^{* * *}$ & $(7.786913)^{* * *}$ & $(7.34145)^{* * *}$ & $(6.798757)^{* * *}$ \\
F-statistic & 57.92631 & 46.23924 & 21.79193 & 14.40844 & 11.65137 \\
\hline
\end{tabular}

Political Terror Scale (PTS) and Gini coefficient are further incorporated into the regression. Surprisingly PTS has a negative relationship with HPI, which implies that political terror actually increases a country's ecological efficiency of delivering human well-being. However, this result should not be over-interpreted as the coefficient lacks statistical power. The Gini coefficient measures the income inequality of a country. Previous studies show evidence that lower Gini coefficient generally associates with higher levels of happiness. This study further supports previous studies that a more equal distribution of income increases human well-being and perceived life satisfaction, by showing that income inequality has a negative relationship with HPI. Overall, the model comprises of ten explanatory variables, and achieved an R-squared of 0.57 , indicating good overall explanatory power. It is also noticeable that the first regression on five macroeconomic variables achieved an R-squared of 0.42 . This shows that macroeconomic factors explain a higher proportion of the variations in HPI values than the social, political variables included in the regression.

\subsection{Granger Causality Test}

In addition to identifying factor determinants, we further study any possible interactions and lead-lag relationship by conducting Granger causality tests on the data. In a VAR system under which Granger causality test is conducted, all variables are assumed stationary, so before the application of VAR model, we need to check the variables for stationarity (Watson, 1994). Since conventional unit root tests such DickeyFuller (DF) and Augmented Dickey-Fuller (ADF) tests show significant limitations in dealing with panel data, specific panel unit root tests are conducted (Barbieri, 2005). We conducted a number of first generation panel unit root tests, and a summary of the results are presented in Table 5.2.

Results from Table 5.2 show that the tests do not produce consistent results, though five variables show evidence of unit root across all four tests: GDP per capita, Inflation, Average annual hours worked, Inflow of 
immigrants, and the Political Terror Scale. I use the first differences of these variables for the subsequent studies. Pairwise Granger causality tests are conducted to analyse the lead-lag relationships between the variables. The results are summarised in Table 5.3, and it shows the F-statistic of variables in the column Granger causing the variable at the top of the column.

Table 5.2

\section{Panel unit root tests}

HPI - Happy Planet Index; GDP - GDP per capita; MSCI - MSCI index, UEMP - unemployment, INFT inflation; AVHR - average annual hours worked; CPI - Corruption Perception Index; INFL, OUTFL Inflow/Outflow of international immigrants; PTS - Political Terror Scale; GINI - Gini coefficient. *** denotes confidence level at $1 \%, * *$ denotes confidence level at 5\%, ${ }^{*}$ denotes confidence level at $10 \%$.

\begin{tabular}{ccccc}
\hline & Levin,Lin \&Chu & Im, Pesaran and Shin W & ADF - Fisher & PP - Fisher \\
\hline HPI & $(-6.70289)^{* * *}$ & $(-4.42067)^{* * *}$ & $(100.318)^{* * *}$ & $(83.809)^{* * *}$ \\
GDP & 0.19727 & 3.19092 & 20.1191 & 19.1342 \\
MSCI & $(-3.72332)^{* * *}$ & $(-1.32904)^{*}$ & 58.4834 & 62.6212 \\
UEMP & $(-3.87382)$ & $(-2.29561)^{* *}$ & $(77.4054)^{* * *}$ & 56.9517 \\
INFT & 3.99401 & 10.0212 & 6.45784 & 16.7054 \\
AVHR & -0.01678 & 2.75163 & 40.0984 & 47.182 \\
CPI & $(-23.4028)^{* * *}$ & $(-7.72508)^{* * *}$ & $(99.5457)^{* * *}$ & $(86.7079)^{* * *}$ \\
INFL & -0.58595 & 1.38775 & 47.0263 & 31.7366 \\
OUTFL & $(-1.71659)^{* *}$ & 1.15182 & 25.5585 & 26.559 \\
PTS & 0.15556 & 0.08689 & 20.9786 & 34.0829 \\
GINI & $(-2.99273)^{* * *}$ & -1.22267 & $(58.4141)^{* *}$ & $(101.242)^{* * *}$ \\
\hline
\end{tabular}

Table 5.3

Pairwise Granger causality tests - Panel unit root tests

\begin{tabular}{|c|c|c|c|c|c|c|c|c|c|c|c|}
\hline & HPI & GDP & MSCI & UEMP & INFT & AVHR & CPI & INFL & OUTFL & PTS & GINI \\
\hline HPI & & 2.31 & $6.61 * * *$ & 2.25 & 0.70 & 0.37 & 0.81 & 0.19 & 0.06 & 1.60 & 0.70 \\
\hline GDP & 0.46 & & 0.16 & $5.69 * * *$ & 0.42 & $2.70 *$ & 0.39 & 0.13 & 0.16 & 1.50 & 1.71 \\
\hline MSCI & $5.52 * * *$ & $42.15 * * *$ & & $24.17 * * *$ & 10.43 & $10.1158 * * *$ & 0.27 & 0.24 & 0.28 & 1.02 & 0.74 \\
\hline UEMP & 0.92 & 0.67 & $3.70 * *$ & & $20.49 * * *$ & $2.34^{*}$ & 0.69 & $7.70 * * *$ & 0.43 & 0.65 & 0.85 \\
\hline INFT & 0.58 & $14.01 * * *$ & 0.21 & $26.32 * * *$ & & $8.09 * * *$ & $3.31 * *$ & $5.30 * * *$ & 0.10 & 1.22 & $3.07 * *$ \\
\hline AVHR & 0.57 & $2.90 *$ & 1.43 & 0.37 & $2.81 *$ & & 2.32 & 0.39 & 0.60 & 2.32 & 0.83 \\
\hline CPI & $3.03 * *$ & 1.57 & 0.23 & 0.92 & $2.52 *$ & $5.06 * * *$ & & 2.52 & 1.29 & 0.37 & 0.18 \\
\hline INFL & 0.46 & 0.08 & 0.49 & $7.63 * * *$ & 0.44 & 0.81 & $3.31 * *$ & & $9.38 * * *$ & 0.55 & 2.05 \\
\hline OUTFL & 2.31 & 0.18 & 0.05 & $2.63 *$ & 0.41 & 1.39 & $3.47 * *$ & 0.76 & & 1.27 & 0.04 \\
\hline PTS & 0.62 & 1.55 & 0.01 & $3.42 * *$ & 0.26 & 0.73 & 0.01 & 1.25 & 1.14 & & 0.15 \\
\hline GINI & 2.19 & 0.15 & 0.56 & 0.28 & 1.24 & 0.03 & $4.24 * *$ & 2.26 & 0.84 & 1.46 & \\
\hline
\end{tabular}

The results show that HPI have significant causal relationships with MSCI and with Corruption Perception Index. HPI and MSCI have a bi-directional causal relationship so that including lagged values of HPI can significantly improve the predicting power of MSCI's VAR equation, and including lagged values of MSCI can also significantly improve the predicting power of HPI. It implies that stock market performance can have a strong predictive power to future HPI values, and vice versa. On the other hand, Corruption Perception Index has a unidirectional causal relationship with HPI, indicating that only lagged value of CPI are significant for the prediction of current value of HPI, but lagged value of HPI cannot predict current CPI value.

This study also identified other lead-lag relationships between the variables studied. There are bi-directional Granger causal relationships between MSCI and Unemployment rate, Inflation and Unemployment, Inflation and Average annual hours worked. These lead-lag relationships show strong interactions between the selected macroeconomic indicators. Of the social-political indicators, HPI, Inflow/outflow of international immigrants and the Gini coefficient Granger causes the Corruption Perception Index. Inflation has a significant causal relationship with the Gini coefficient, showing that inflation can be used to predict the degree of income inequality. 


\section{CONCLUSIONS}

This paper studies the new well-being measure, the Happy Planet Index, and analyses a range of potential factor determinants of the index. This paper further studies the lead-lag relationships between the variables. A panel dataset comprising 25 OECD countries over a period of 16 years from 1994 to 2009 is employed for the study. This paper finds that conventional microeconomic indicators have strong statistical relationships with HPI, though higher levels of income does not necessarily mean higher levels of well-being, or higher ecological efficiency in delivering well-being. This study also finds some significant causal relationships between HPI and the explanatory variables, and lead-lag relationships are evident.

Further studies can be directed at identifying and including further social, cultural, and political factors in the regression model, which can help improve both the power and the efficiency of the regression analysis. With better data availability, comparative studies of both developed countries and developing countries can also potentially yield interesting results, particularly on how growth in wealth can impact HPI values differently in countries with different income levels.

\section{REFERENCES}

Abeygunawardana, A. 2010, A Yardstick for the New World - Happy Planet Index. Retrieved $17^{\text {th }}$ December, 2010, from: http://www.efsl.lk/publications

Barbieri, L. 2005, Panel Unit Root Tests: A Review. Piacenza: Università Cattolica del Sacro Cuore Online Available on http://www3.unicatt.it/unicattolica/dipartimenti/DISES

Brooks, C. 2008, Introductory Econometrics for Finance. $2^{\text {nd }}$ Edition. Cambridge University Press

Corruption Perception Index. 2010, Retrieved on 19 $9^{\text {th }}$ April, 2011, from http://www.transparency.org/policy_research

Di Tella, R., MacCulloch, R., Oswald, A. 2001, Preferences over inflation and unemployment: evidence form surveys of happiness. The American Economic Review ,91 (1), 335- 341.

Frey, B., Stutzer, A. 2002, The Economics of Happiness. World Economics, 3, 1-17.

Granger, C. 1969. Investigating casual relations by economic models and cross-spectral methods. Econometrica, 37, 24-36.

Happy Planet Index List. (2010). What is the Happy Planet Index

Retrieved $17^{\text {th }}$ December, 2010, from: http://www.earthsfriends.com/happy-planet-index-list

Hoffmann, R., Lee, C., Ramasamy, B., and Yeung, M. 2005, FDI and Pollution: a Granger Causality Test Using Panel Data. Journal of International Development, 17, 311-317.

Hurlin, C., Venet, B. 2001, Granger causality tests in panel data models with fixed coefficients. Working Paper. EURIsCO, Universit'e Paris IX Dauphin.

Kenny, C. 1999, Does Growth Cause Happiness, or Does Happiness Cause Growth? KYKLOS, 52, 3-26.

Marks, N., et al. 2006, The Happy Planet Index (New Economics Foundation, London). Retrieved $10^{\text {th }}$ April, from: http://www.happyplanetindex.org

Ng, Y. 2008, Environmentally Responsible Happy Nation Index: Towards an Internationally Acceptable National Success Indicator. Social Indicators Research, 85, 425-446.

Political Terror Scale. 2011, Retrieved 19 ${ }^{\text {th }}$ April, 2011, from: http://www.politicalterrorscale.org/

The Happy Planet Index. (2009). Retrieved 19 April, 2011, from: http://www.neweconomics.org/projects/happy-planet-index

Thompson, S., Marks, N., Abdallah, S., Matthews, E. (2007). Contribution to Beyond GDP "Virtual Indicator Expo". Retrieved $17^{\text {th }}$ December, 2010, from: http://www.beyond-gdp.eu

Watson, M. 1994, Vector Autoregressions and Cointegration. Handbook of Econometrics (vol IV). Elsevier Science B.V. 